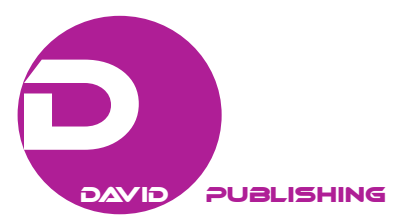

\title{
Recommendations for Using Wiki in Online Group Projects in Engineering Education
}

\author{
Gláucia Nolasco de Almeida Mello \\ Pontifical Catholic University of Minas Gerais, Belo Horizonte, Brazil
}

\begin{abstract}
Although Web 2.0 tools like blogs and wikis have been used for supporting collaborative learning in higher education, there are not many reports about implementation of that resource on engineering in Brazil. In this way, the main purpose of this research is to use a wiki platform for online activities and evaluate how students collaborate with each other in online tasks. It was investigated how collaboration can be measured on wiki platform. During four-week online activities, 40 students of Civil Engineering course were monitored on Wikispaces ${ }^{\circledR}$ platform. All students' actions were analyzed and classified as low, medium, or high level of collaboration. The data were collected through the statistical reports of Wikispaces ${ }^{\circledR}$ and Google Analytics platforms. It computed 336 students' actions: $16.67 \%$ as high level, $45.24 \%$ as medium, and $38.10 \%$ as low. During informal interview, most of students (70\%) related that wiki was a nice tool for collaboration work. The results indicated that wiki platform is an important way to develop innovative activities and tasks for the purpose of improving engineers' abilities and skills such as: writing communication, organization, collaboration, and critical thinking development.
\end{abstract}

Keywords: wikis and higher education, wiki-based project, collaborative activities online, measuring collaboration online

\section{Introduction}

The fast evolution of Information and Communication Technology (ICT) during the past two decades determined the way that people communicate, socialize, and learn. This event introduced a new generation of learners that have adopted mobile devices and Web 2.0 technologies such as Facebook ${ }^{\circledR}$ (facebook.com), Twitter ${ }^{\circledR}$ (twitter.com), YouTube ${ }^{\circledR}$ (youtube.com), Flickr ${ }^{\circledR}$ (flickr.com), blog, wiki, etc. to get information and communicate (May, Lensing, Tekkaya, \& Grosch, 2014; Telefônica Foundation, 2014). Web 1.0 technology was composed by applications focus on the content delivery. The next generation, Web 2.0, focus more on content creation by own user and social connectivity (O’Reilly \& Battelle, 2005; Bennett, Bishop, Dalgarno, Waycott, \& Kennedy, 2012). According to some authors (O’Reilly \& Battelle, 2005; Bennett et al., 2012; Hew \& Cheung, 2013; Campión, Nalda, \& Rivilla, 2012), Web 2.0, also called “social media”, could be defined by a set of definition tools and resources that allow high level of interactivity and communication between individuals. The Web 2.0 tools, such as blogs, wikis, podcasts, social bookmarking, photo sharing, instant

Gláucia Nolasco de Almeida Mello, Dr., adjunct professor, Civil Engineering Department, Pontifical Catholic University of Minas Gerais, Belo Horizonte, Brazil.

Correspondence concerning this article should be addressed to Gláucia Nolasco de Almeida Mello, Civil Engineering Department, Pontifical Catholic University of Minas Gerais, Av. Dom José Gaspar, 500 Prédio 3-sl 102, Coração Eucarístico, Belo Horizonte MG, CEP 30535-901, Brazil. 
messaging, etc., offer huge possibilities for collaboration as well. Especially for Brazilians, Telefônica Foundation (2014) reported that huge part of youth use social media to communicate and learn. They monitored and interviewed 1,440 Brazilian young people (16 to 24 years old) from all regions of the country to investigate about the internet habit of Brazilian students. They reported that $42.0 \%$ of Brazilian students use the mobile as main device to connect to the internet. The main Brazilian youth internet activities are communication (37.3\%) followed by leisure (29.6\%), reading (28.7\%), and learning and education (28.1\%).

\section{Wikis and Higher Education}

Ward Cunningham in 1995 introduced the concept of wikis when created the first wiki website known as Wiki Wiki Web (Wiki-Wiki-Web ${ }^{\circledR}$ Website, 2015). The Hawaiian word for quick, wikiwiki, was the inspiration for the term wiki (Ebner, Kickmeier-Rust, \& Holzinger, 2008; Abreu, Silva, Mendes, \& Vinhas, 2012). Further implementations of wiki platforms were CoWeb and Nupedia in 2000. The last one was succeeded by Wikipedia ${ }^{\circledR}$ (http://www.wikipedia.org) which was established in 2001 by Jimmy Wales and Larry Sanger (Guzdial, Hmelo, Hübscher, Nagel, Newstetter, Puntembakar, Shabo, Turns, \& Kolodner, 1997). Wikipedia ${ }^{\circledR}$ is an online editable multi language (about 250 different languages) encyclopedia that included topics published by common users from around the world. Wiki pages such as Wikipedia ${ }^{\circledR}$ can be composed by a variety of content e.g., text, images, graphs, and videos.

There are different software and platform and freely available on the internet for creating wikis, for example, MediaWiki ${ }^{\circledR}$ (https://www.mediawiki.org), TWiki ${ }^{\circledR}$ (http://twiki.org), DokuWiki ${ }^{\circledR}$ (https://www. dokuwiki.org) and Wikispaces ${ }^{\circledR}$ (http://www.wikispaces.com). MediaWiki ${ }^{\circledR}$, TWiki ${ }^{\circledR}$, and DokuWiki ${ }^{\circledR}$ are open source wiki software that is especially useful for web application and enterprise context. All of these three kinds of software mentioned before you must download the newest release from the corporation website, unpack and install/copy the files to your web space but some web server administration skill is necessary. Developers can extend the functionality of them with Plugins-programs that can easily be installed and used as part of the wiki software. In contrast, Wikispaces ${ }^{\circledR}$ is an online platform and it is not necessary to download and install software. Wikispaces ${ }^{\circledR}$ also provides a statistical report about the usage of the projects, i.e., pages accessed and date of access for all wiki project users. Most of wiki software/platform freely available can be applied for educational projects so educators should identify the features that are essential for the activity and depending on these features the best wiki software/platform might be chosen.

According to the University of Delaware's report (2008), wiki can be classified into pure or hybrid as well. Hybrid wiki is moderated by experts, is private and users and changes are tracked. Those characteristics are suitable for education projects or activities because mediators can monitor the learners and their actions inside the wiki platform. Nevertheless, both pure and hybrid wiki can be used to support many different activities like brainstorming, group project, meeting support, make lists, collections of links, writing a collective web content, and building a group portfolio. Table 1 presents the main features of pure and hybrid wikis.

Researchers have conducted investigations to assess the actual use of wiki tools in the educational context. Abreu et al. (2012) conducted a survey was filled by 12 professors and 136 students who were involved in wiki-based tool activities. Based on the survey analyses, they affirmed that wikis are a solid technology elected and recognizable for a significant part of users. Gomes and Sousa (2013) introduced some activities to Information System Management classes whose the objective was to validate the desired Wiki outcomes for teaching and learning process. They concluded that teaching and learning through wikis platforms can 
contributes greatly to the development of teamwork processes, self-organization, integrity, and openness. In order to examine the use of wikis in English as a Foreign Language writing classroom, Wang (2014) investigated how wikis can facilitate collaboration and promote foreign language acquisition. Her findings suggested that wikis "increase the students' motivation to learn English enhance their writing confidence and promote their initiatives for social constructivist".

Table 1

Pure Wiki x Hybrid Wiki

\begin{tabular}{|l|l|l|}
\hline & Pure wiki & Hybrid wiki \\
\hline Access & $\bullet$ Anonymous & $\bullet$ Users and changes are tracked \\
\hline Content & $\begin{array}{l}\bullet \text { Public domain } \\
\text { Structure }\end{array}$ & $\begin{array}{l}\bullet \text { Copyrighted or private } \\
\bullet \text { Embedded images/videos/applications }\end{array}$ \\
\hline \multirow{3}{*}{ Workspace } & $\begin{array}{l}\bullet \text { Unstructured } \\
\bullet \text { Consensus of its community }\end{array}$ & $\begin{array}{l}\bullet \text { Template-driven/Workflow-driven } \\
\bullet \text { Moderated by experts }\end{array}$ \\
\hline Time & $\bullet$ Anyone may read and edit any page & $\begin{array}{l}\bullet \text { Permissions for users and pages } \\
\text { Private }\end{array}$ \\
\hline
\end{tabular}

Source: Adapted from Lamb (2004) and University of Delaware (2008).

\section{Interactivity and Collaboration}

Interactivity. Ebner et al. (2008) presented two characteristics of technology-enhanced learning that wikis highly support: interactivity and freedom. Learners are able to get and improve knowledge and solve problems in a cooperative way through interaction with content, with professors, and with other students. The authors also emphasize the level of students' freedom in a wiki environment is an important success factor of learning once it is possible to access it anytime, anywhere by anybody. According to Lamb (2004) and James (2014), to provide interactivity and freedom, some rules are essential for a truly wiki project: all users may change anything, it must be provided simplified hypertext markup, sense of authorship and ownership is not allowed, content must be organized by context instead of chronology, main focus must be on content not on format, and content organization must be defined by the community.

Collaboration. Vygotsky introduced the concept of Zone of Proximal Development (ZPD), defined as the "distance between the actual developmental level as determined by independent problem-solving and the level of potential development as determined through problem solving under adult guidance or in collaboration with more capable peers” (Vygotsky, 1978). His social-cultural learning theory originally refers to expert-novice or teacher-student interactions but it has been applied to supportive behaviors by which students can help each other in the classroom or online platform (Guerrero \& Villamil, 2000; Li \& Zhu, 2013; Cicconi, 2014; Hadjerrouit, 2014). Online platforms offer new opportunities to work in groups, such as, wiki platforms with high interactivity potential that enables users to create and edit online hypertexts easily (Gomes \& Sousa, 2013; Cheuk-Hang \& Wei, 2014; Wang, 2014). Editions and revisions can be made directly in the text and the changes can be synchronized or not. In the discussion page, students can argue about the specific subject and consequently they are encouraged to construct knowledge and develop critical thinking. In addition, previous research results demonstrated that wikis are also an efficient platform to measure collaboration (Lamb, 2004; University of Delaware, 2008; Hadjerrouit, 2014). Wiki platforms provide tools that enable professors to evaluate individually the student's contribution level through history log and statistics resources. Despite the 
advantages of wiki platforms, students should be encouraged to collaborate with each other to make revisions on the text because most of learners are inclined to work independently of each other without peer support (Hadjerrouit, 2014; Wang, 2014).

Research questions. ICT and Web 2.0 technologies can support teaching/learning process and improve important students' abilities from the 21st century providing to them opportunity to get control of your own learning process. The wiki technology, specially, is a great tool to improve collaboration and critical thinking skills (Gomes \& Sousa, 2013; Cheuk-Hang \& Wei, 2014; Wang, 2014; Wake \& Modla, 2012).

Although there are many reports about using wiki tool in educational environments, there is a lack of report about how to apply wiki resource in engineering education. In this way, the following questions were addressed to explore the characteristics of wikis for improving the abilities and skills of students:

1. How should collaboration be effectively measured on wiki platform?

2. What should be considered in wiki-based project for engineering education?

The following session of this article details an example of its application in civil engineering education and the methodology adopted to measure collaboration on wiki platform. Next session presents the obtained results. Conclusions that can be withdrawn from the research are presented in the last session.

\section{Methodology}

\section{Participants}

A total of 40 students of the forth-year university from a face to face Civil Engineering course were asked to register on Wikispaces ${ }^{\circledR}$ platform to participate in four-week online activities. All of participants were enrolled in Reinforced Concrete Structures which is a compulsory discipline in Civil Engineering course. Students were randomly assigned to a group and each group was composed of eight students. Participation in the wiki project was a complimentary part of the course as homework task. All students had experience with working in groups, but none of them were familiar with wiki-based collaborative writing.

\section{Wiki Platform}

It chose Wikispaces ${ }^{\circledR}$ Classroom platform (http://wikispaces.com) as the project because it is a social writing platform for education suitable for collaborative learning. Some important characteristics of that platform are: (a) students can use it easily; (b) teacher and students can communicate and work on writing projects alone or in teams; (c) it provides assessment tools that give teachers the power to measure student contribution and engagement in real-time; and (d) it is possible to implement a hybrid wiki. Furthermore it works on modern browsers, tablets, and smart phone.

\section{Activities on Wikispaces ${ }^{\circledR}$ Platform}

Wiki-based project started on 24th November, 2014 and finished on 19th December, 2014. The first week of the project was reserved to introduce to students the main technical features of Wikispaces' platform. During this week they learned about the text editor and also about platform's main resources they need to edit and revise texts and communicate with peer. The project was detailed to students on the web environment, i.e., all information about the group tasks, production of final online pages, and assessment were posted in home page of wiki-based project.

The research theme was Reinforced Concrete Water Tank that makes part of content of Reinforced Concrete discipline. Five specific topics were chosen to be researched for this project: (1) Pathologies of 
concrete water tank; (2) Precast concrete water tank; (3) Underground water tank; (4) Elevated water tank; and (5) Ground water tank. The topics were randomly distributed to each group. Students worked together during the next two weeks in order to create a wiki document. All groups should develop informative online pages in Wikispaces ${ }^{\circledR}$ platform about their topic containing the following: (a) an overview, (b) theoretical rationale, (c) advantages, (d) disadvantages, and (e) practical applications. Students were provided with list of references with articles, books, and technical magazines available at university library. They were allowed to use additional resources like internet information. In this way, they were instructed to be careful, i.e., all internet information must be reliable and copyright must be preserved.

Two tasks were timetabled for each group. The first task—overview, theoretical rationale—started on 29th November and the maximum deadline for publications was 8th December. The second task-advantages, disadvantages, and practical applications — was timetabled to start on 9th December and the maximum deadline to finish task was 14th December. Forth week of the project was dedicated to professor's feedback.

\section{Results}

Statistical analysis, analysis of the editions, revisions, and comments, and informal interview were the instruments of data collection. The statistical analysis used in this study was provided by the Wikispaces ${ }^{\circledR}$ and Google Analytics ${ }^{\circledR}$ platforms. From Wikspaces ${ }^{\circledR}$ platform, what considered are number of editions, revisions, and comments. All particular student data, such as when, what, and how many times the students assigned to a session in the platform; the content of their messages, editions, and revisions also were taken from Wikspaces ${ }^{\circledR}$ platform. Stay length, most visited pages, and technology used to access were taken from Google Analytics ${ }^{\circledR}$.

\section{Collaboration in the History Log and Comments Space}

Many aspects of wiki member can be measured such as amount of times accessed, number editions, revisions, and comments, etc. On revisions, for example, students can contribute to a wiki in many ways: add and remove new content, restructure existing content, revise text grammar and sentences, etc. Pfeil, Zaphiris, and Ang (2006) in their work about cultural differences in Wikipedia ${ }^{\circledR}$ collaboration editions categorized the editions types that were subdivided by authors into 13 possible actions: add information, add link, clarify information, delete information, delete link, fix link, format contributions, grammar alterations, mark-up language changes, reversion that is related to reverse vandalism action, spelling correction, style/typography contributions, and vandalism entries/actions. Based on the Pfeil, Zaphiris, and Ang's (2006) recommendations, the editions in this wiki project were categorized as shown in Table 2.

The mark-up language category was not considered because creating a document on the Wikispaces' text editor is not necessary to use HTML code. Vandalism and reversion were not taken into account because the wiki project had not a public access. In addition, all edition categories have not the same importance degree in online activity. Moreover, to facilitate the verification of collaboration level, the categories were grouped by three levels of importance: (1) low, actions related to text format; (2) medium, actions related add or delete information; and (3) high, actions that clarify or modify information and grammar and spelling alterations. Table 2 summarizes all possible actions for editions and revisions and its collaboration level.

Wikispaces ${ }^{\circledR}$ platform also has space for comments and all of them were also analyzed. All comments were categorized the same way of edition, i.e., (1) low, comments related to text format, technical questions, or 
discussions about deadline and task division; (2) medium, comments related to the topic (adding information); and (3) high, support comments related to clarify or modify information, and fix mistakes.

Final grade was composed by statistic results (medium and high level of collaboration) and evaluation of the constructed pages. All page editions were categorized as medium level of collaboration, revisions were classified as low or high level, see Table 2. And comments could be considered low, medium, or high level of collaboration. For pages' evaluation was taken into account content, organization, and bibliographic references. Groups 5 and 1 developed complete wiki pages with all required information; pages of these groups also had organized structure and extra information such as images, videos, and links. There were 100 editions, 104 revisions, and 132 comments and the groups 1 (26.19\% of actions) and 5 (34.82\% of actions) had better participation and the pages created by them met all requirements defined before. Total number of editions, revisions, comments, and the percentage of all actions for each group are shown in Table 3 that also presents the final grade.

Table 2

Categorization of Wiki Editions and Revisions of Pages

\begin{tabular}{|l|l|l|l|}
\hline Category & Action & Explanation & Collaboration level \\
\hline \multirow{5}{*}{ Edition } & Add information & Addition of information related to the topic (text, link, video, etc.). & Medium \\
\cline { 2 - 5 } & Delete information & Delete of information related to the topic (text, link, video, etc.). & Medium \\
\hline \multirow{5}{*}{ Revision } & Clarify information & $\begin{array}{l}\text { Contributions related to the appearance, presentation or structure of } \\
\text { the text or page (addition of space lines, sorting/moving of } \\
\text { paragraphs or links and addition of subtitles in order to structure the } \\
\text { content, bold/ italic/underlined text). }\end{array}$ & Low \\
\cline { 2 - 5 } & $\begin{array}{l}\text { Rewording of existing information adding or not a new } \\
\text { information to clarify the content (e.g., substitution of certain words } \\
\text { for a better understanding, change of the word order or deletion/ } \\
\text { addition of words in order to clarify). }\end{array}$ & High \\
\cline { 2 - 5 } & Modify information & $\begin{array}{l}\text { Modification of an existing information like an alteration of the } \\
\text { linked URL, image, video or text) }\end{array}$ & High \\
\cline { 2 - 5 } & Grammar and spelling & $\begin{array}{l}\text { Alterations of the grammar (e.g., change of punctuation) and } \\
\text { correction of spelling mistakes (e.g., reversed letters or capital } \\
\text { letter, spelling errors). }\end{array}$ & High \\
\hline
\end{tabular}

Source: Adapted from Pfeil, Zaphiris, and Ang (2006).

Table 3

Editions, Revisions, Comments and Final Grade by Group

\begin{tabular}{lllllll}
\hline Group & Edition & Revision & Comment & Total & $\%$ & Final grade \\
\hline 1 & 37 & 37 & 14 & 88 & 26.19 & 5.00 \\
2 & 4 & 10 & 29 & 43 & 12.80 & 3.50 \\
3 & 18 & 19 & 24 & 61 & 18.15 & 4.50 \\
4 & 6 & 1 & 20 & 27 & 8.04 & 2.00 \\
5 & 35 & 37 & 45 & 117 & 34.82 & 5.00 \\
\hline
\end{tabular}

Graphic in Figure 1 shows low, medium, and high level of collaboration by group: 16.66\% of all collaboration was categorized as high level, $45.24 \%$ as medium level, and $38.10 \%$ as low level. Group 5 had the best participation with 5.95\% of high level collaboration and $16.96 \%$ of medium level of collaboration; and group 4 had the worse participation with $1.19 \%$ of high level contributions and $4.76 \%$ of medium level contributions. 


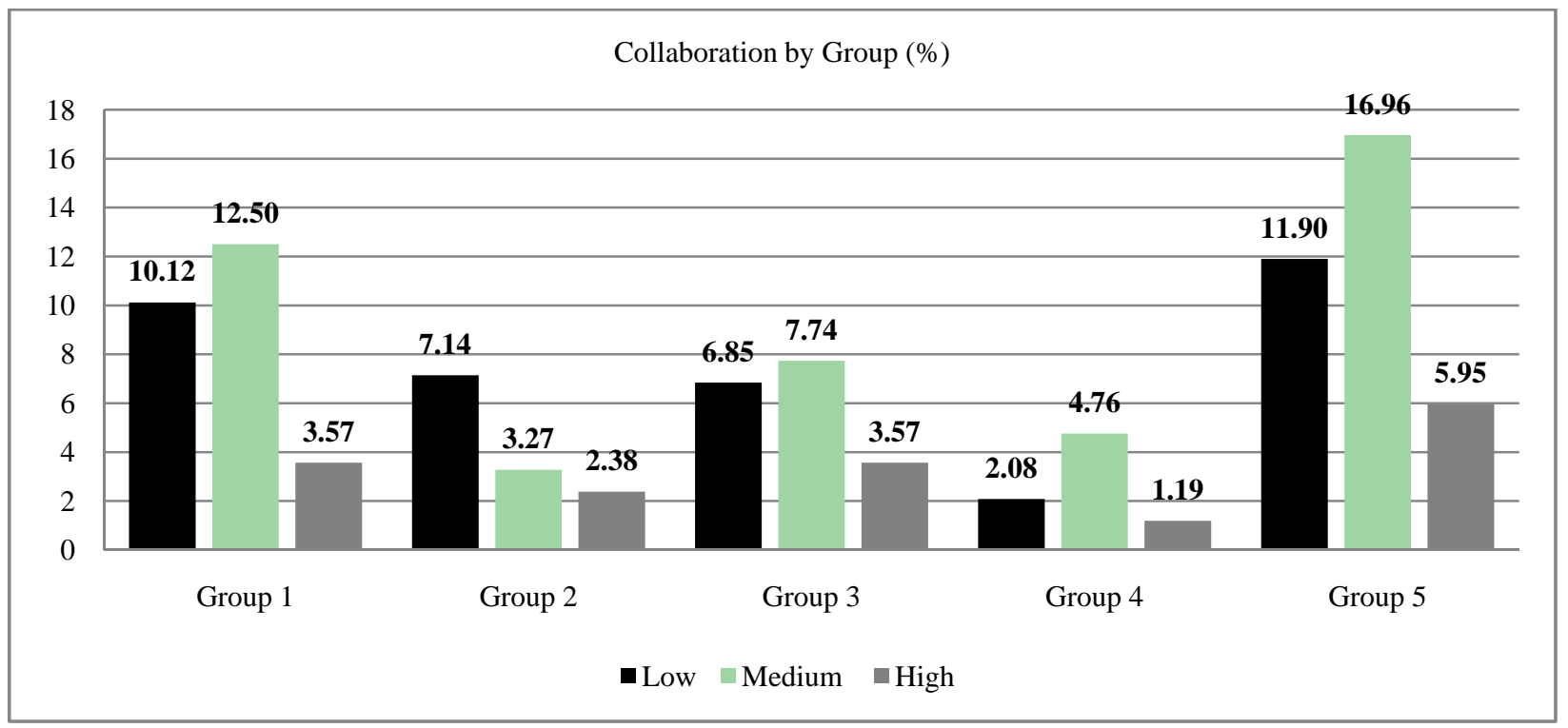

Figure 1. Low, medium, and high level of collaboration by group.

Participation of each student was evaluated by the number of medium and high level of editions, revisions, and comments they made. Table 4 presents the collaboration's level percentage by student in the wiki project. A total of 40 students assigned to the wiki project but eight of them did not participate (Table 4), $80 \%$ of students contributed to the project. This wiki project had 336 actions computed, which means an average of 10.5 actions per student considering just assigned students that participate effectively (32).

Table 4

Collaboration Level by Student and Group

\begin{tabular}{|c|c|c|c|c|c|c|c|c|c|c|}
\hline \multirow{2}{*}{ Group } & \multirow{2}{*}{ Collaboration level } & \multicolumn{8}{|c|}{ Student } & \multirow{2}{*}{$-(\%)$} \\
\hline & & 1 & 2 & 3 & 4 & 5 & 6 & 7 & 8 & \\
\hline \multirow{3}{*}{1} & Low & 1.79 & 1.19 & 2.38 & 0.00 & 1.19 & 1.49 & 1.49 & 0.60 & 10.12 \\
\hline & Medium & 3.27 & 1.79 & 0.89 & 0.00 & 1.49 & 1.19 & 2.08 & 1.79 & 12.50 \\
\hline & High & 1.49 & 0.00 & 0.60 & 0.00 & 0.00 & 0.60 & 0.30 & 0.60 & 3.57 \\
\hline \multirow{3}{*}{2} & Low & 0.60 & 1.19 & 0.89 & 0.00 & 1.49 & 1.19 & 1.19 & 0.60 & 7.14 \\
\hline & Medium & 0.00 & 0.30 & 0.30 & 0.00 & 0.60 & 0.89 & 0.60 & 0.60 & 3.27 \\
\hline & High & 0.60 & 0.89 & 0.89 & 0.00 & 0.00 & 0.00 & 0.00 & 0.00 & 2.38 \\
\hline \multirow{3}{*}{3} & Low & 1.79 & 0.00 & 1.19 & 0.89 & 1.19 & 0.60 & 0.00 & 1.19 & 6.85 \\
\hline & Medium & 2.08 & 1.79 & 0.00 & 0.89 & 1.19 & 0.89 & 0.00 & 0.89 & 7.74 \\
\hline & High & 1.79 & 0.00 & 0.00 & 0.30 & 0.60 & 0.89 & 0.00 & 0.00 & 3.57 \\
\hline \multirow{3}{*}{4} & Low & 0.30 & 0.30 & 0.30 & 0.00 & 0.30 & 0.30 & 0.60 & 0.00 & 2.08 \\
\hline & Medium & 0.89 & 0.60 & 0.89 & 0.00 & 0.89 & 0.30 & 1.19 & 0.00 & 4.76 \\
\hline & High & 0.00 & 0.00 & 0.60 & 0.00 & 0.00 & 0.60 & 0.00 & 0.00 & 1.19 \\
\hline \multirow{4}{*}{5} & Low & 2.38 & 3.57 & 1.49 & 2.08 & 0.00 & 2.38 & 0.00 & 0.00 & 11.90 \\
\hline & Medium & 3.57 & 2.68 & 2.08 & 4.17 & 0.00 & 4.46 & 0.00 & 0.00 & 16.96 \\
\hline & High & 1.79 & 1.79 & 0.60 & 0.60 & 0.00 & 1.19 & 0.00 & 0.00 & 5.95 \\
\hline & & & & & & & & & & 100.00 \\
\hline
\end{tabular}

Reinforced Concrete Water Tank wiki project was accessed 3,327 times. All participants were allowed to visit any page, but they could edit only the pages of their group. The most visited pages were pages of group 5 
as shown in Figure 2. Access to the project was concentrated on the second and third weeks of the project and the days leading up to the deadline to delivery finished tasks were the ones that had the most number of visits, see graphic in Figure 2.

It conducted an informal interview with 10 students that had participated effectively. They should answer just one question:

Which are the positives and negative points of Wikispaces ${ }^{\circledR}$ project?

The main students' reports about positive points were: (1) possibility to choose time and place to do the tasks; (2) possibility to visit pages of all groups; and (3) students are encouraged to collaborate more. And the main negative points were: (1) difficulty to understand the platform, mainly the text editor; and (2) some students do not answer the mails because they have to access the platform.

Most of students (70\%) related that wiki was a nice tool for collaboration work and file sharing despite of the negative points reported. Some students (40\%) indicated preferences on using other platform because they think that it is difficult to execute some operations and commands on Wikispaces ${ }^{\circledR}$ text editor such as inserting images.

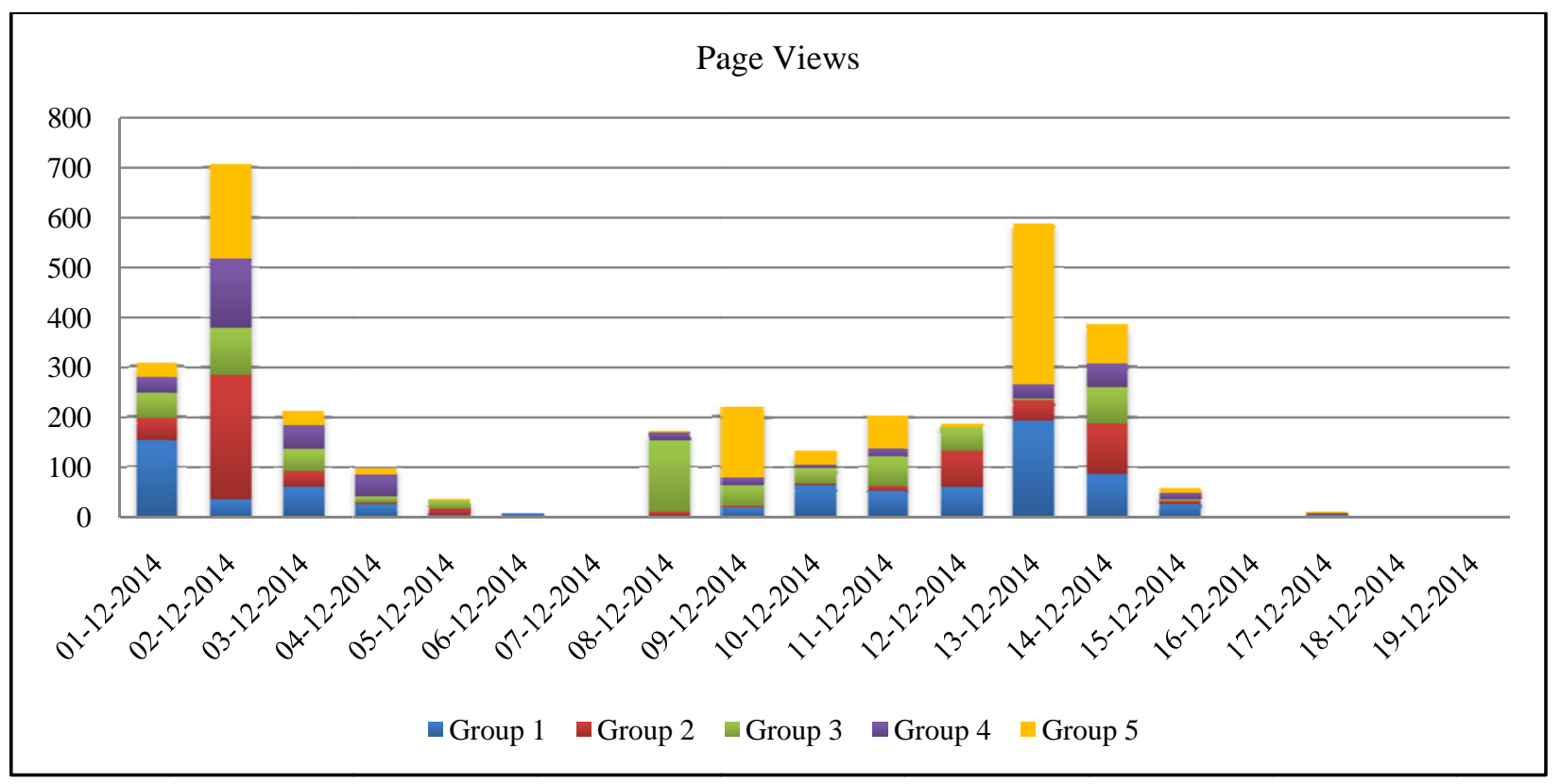

Figure 2. Group page’s views.

\section{Discussion and Conclusion}

The main objectives of this study were: to explore the possibility of use wikis as pedagogical resource, to observe the level of collaboration between students in a wiki platform, and to identify the challengers of using wiki in engineering education tasks. All five groups created digital learning material on Wikispaces ${ }^{\circledR}$ platform about a specific subject of civil engineering. Data collected from statistic reports and informal interview were analyzed to answer the research questions.

\section{First Question: How Should Collaboration Be Measured on Wiki Platform?}

Measuring collaboration in wikis by counting number of editions, revisions, and comments is not enough to educational purpose. These parameters indicate the participation degree but they would not show the 
collaboration level among the group members. To be more accurate in the collaboration measurement, it was necessary to identify all possible types of collaboration actions in wiki platform. In addition, it is also necessary to categorize actions by levels: low, medium, and high. The results demonstrated that the applied categorization was efficient to classify all actions in three levels of student participation and can be used to assess collaboration in wiki projects.

\section{Second Question: What Should Be Considered in Wiki-based Project for Engineering Education?}

Specific challenges were noticed when new technologies and methodologies, especially wikis, are implemented in higher education practices. The first one is that almost all the students do not know how to really collaborate with each other. To add and delete information were the more frequent collaborative actions (45.24\%) identified in this online project and they were classified as medium level. It was also possible to observe that some groups may have good high-level collaboration, and others remain superficial or do not exist. In this way, it would be efficient to explain in detail all possible actions on wiki platform and its categorization and emphasizing the actions of high level collaboration.

Second one is that people are very competent in using ICTs in their daily lives but they need support to integrate technologies into teaching and learning process. Before introducing technological tools in their classes, professors have to be sure about the importance of pedagogy over technology. In this way, some suggestions are presented: (1) rethink the pedagogy in accordance to chosen technology to achieve good results; (2) plan content and teaching strategies for specific online platforms; and (3) spent some classes to demonstrate the functionality of the platform, including the text editor. Students are not always familiar with using technology in their learning process, they need support. As it was demonstrated through the results, students reported faced challenges to edit and format text and insert images on Wikispaces ${ }^{\circledR}$ platform. They think that a more user-friendly WYSIWYG edition mode could be provided by online platforms.

And finally, according to Waycott, Sheard, Thompson, and Clerehan (2013), the use of social technologies in higher education could introduce new tensions for students and teachers when (1) students make their work visible to others; (2) teachers challenge the rules and established practices associated with university assessment; and (3) introduce new practices and pedagogical approaches. Meanwhile, Smith, Sheppard, Johnson, and Johnson (2005) reported that learning opportunities inside and outside classroom (diversity, technology, collaboration, community service, etc.) enhance learning. In addition, students are motivated and satisfied with schools that actively promote learning and stimulate social interaction (Smith et al., 2005). It is appropriate to students be comfortable with how they represents themselves in online environment so it is convenient to educate students about taking care when publishing their work on social medias (Waycott et al., 2013). To minimize the impact of new approaches' implementation, professors should consider negotiating with university the rules for assessment and paying attention on pedagogical aspects related to online learning.

Despite of all challenges, wiki platform is an important way to develop innovative activities and tasks based on learner-centered approach (LCA) in online environment. Wiki-based project provides opportunity for learners to participate actively in their own learning process; pedagogical activities in online environment can contribute to pro-active and collaborative writing and furthermore, wikis can improve the teaching and learning process greatly once it can contribute to development of students' abilities and skills such as: creative writing, organization, and critical thinking development. 
Especially in engineering education, hybrid wiki can be used to support different activities like brainstorming, group project, and writing collective web content. It is important to clarify that the basic idea behind this proposed approach is not to discard the traditional classroom teaching method, but to create complementary alternatives, which aid lectures to improve student's engagement.

\section{References}

Abreu, P., Silva, D. C., Mendes, P., \& Vinhas, V. (2012). Effect of the usage of Wikis on an educational context. Wiley Periodicals: Computer Applications in Engineering Education, 20, 646-653.

Bennett, S., Bishop, A., Dalgarno, B., Waycott, J., \& Kennedy, G. (2012). Implementing Web 2.0 technologies in higher education: A collective case study. Computer \& Education, 59, 524-534.

Campión, R. S., Nalda, F. N., \& Rivilla, A. M. (2012). Web 2.0 and higher education: Its educational use in the university environment. European Journal of Open, Distance and E-Learning, 2, 1-18.

Cheuk-Hang, A. U., \& Wei, H. E. (2014). Using Wiki for project collaboration-With comparison on Facebook. World Congress on Engineering and Computer Science, 1, 22-24.

Cicconi, M. (2014). Vygotsky meets technology: A reinvention of collaboration in the early childhood mathematics classroom. Early Childhood Educ J, 42, 57-65.

Ebner, M., Kickmeier-Rust, M., \& Holzinger, A. (2008). Utilizing Wiki-systems in higher education classes: A chance for universal access? Springer Periodicals: Universal Access in the Information Society, 7(4), 199-207.

Gomes, R., \& Sousa, L. (2013). Teaching and learning through Wikis in higher education. International Journal of Information and Education Technology, 3(6), 628-633.

Guerrero, M. C. M. de, \& Villamil, O. S. (2000). Activating the ZPD: Mutual scaffolding in L2 peer revision. The Modern Language Journal, 84, 51-68.

Guzdial, M., Hmelo, C., Hübscher, R., Nagel, K., Newstetter, W., Puntembakar, S., Shabo, A., Turns, J., \& Kolodner, J. L. (1997). Integrating and guiding collaboration: Lessons learned in computer-supported collaborative learning research at Georgia Tech. The 2nd Conference on Computer Support for Collaborative Learning 1997, 1, 95-105. Toronto, Canada.

Hadjerrouit, S. (2014). Wiki as a collaborative writing tool in teacher education: Evaluation and suggestions for effective use. Computers in Human Behavior, 32, 301-312.

Hew, K. F., \& Cheung, W. S. (2013). Use of Web 2.0 technologies in K-12 and higher education: The search for evidence-based practice. Educational Research Review, 9, 47-64.

James, R. (2014). ICT's participatory potential in higher education collaborations: Reality or just talk. British Journal of Educational Technology, 45(4), 557-570.

Lamb, B. (2004). Wide open spaces: Wikis, ready or not. EDUCAUSE Review, 39(5), 36-48. Retrieved from http://er.educause.edu/articles/2004/1/wide-open-spaces-wikis-ready-or-not

Li, M., \& Zhu, W. (2013). Patterns of computer-mediated interaction in small writing groups using wikis. Computer Assisted Language Learning, 26(1), 61-82.

May, D., Lensing, K., Tekkaya, A. E., \& Grosch, M. (2014). What students use-results of a survey on media use among engineering students. IEEE Frontiers in Education Conference, 1, 92-97.

O’Reilly, T., \& Battelle, J. (2005). What is web 2.0? Design patterns and business models for the next generation of software. Retrieved from http://www.oreillynet.com/pub/a/oreilly/tim/news/2005/09/30/what-is-web-20.html

Pfeil, U., Zaphiris, P., \& Ang, C. S. (2006). Cultural differences in collaborative authoring of Wikipedia. Journal of Computer-Mediated Communication, 12(1), 88-113.

Telefônica Foundation (org.). (2014). Juventude Conectada. São Paulo: Telefônica Foundation. Retrieved from http://www.fundacaotelefonica.org.br/conteudos/publicacoes/Detalhe.aspx?id=137

University of Delaware (org.). (2008). Wikis in higher education. Newark, DE: University of Delaware, IT-User Services. Retrieved from http://udel.edu/ mathieu/wiki/resources/2008-5-23_Wikis_in_Higher_Education_UD.pdf

Vygotsky, L. S. (1978). Mind and society: The development of higher mental processes. Cambridge: MA, Harvard University Press.

Wake, D. G., \& Modla, V. B. (2012). Using wikis with teacher candidates: Promoting collaborative practice and contextual analysis. Journal of Research on Technology in Education, 44(3), 243-265. 
Wang, Y.-C. (2014). Using wikis to facilitate interaction and collaboration among EFL learners: A social constructivist approach to language teaching. System, 42, 383-390.

Wiki-Wiki-Web® Website. (2015). Cunningham, Ward. Retrieved from http://c2.com/cgi/wiki?WelcomeVisitors

Waycott, J., Sheard, S., Thompson, C., \& Clerehan, R. (2013). Making students’ work visible on the social web: A blessing or a curse? Computers \& Education Journal, 68, 86-95.

Smith, K. A., Sheppard, S. D., Johnson, D. W., \& Johnson, R. T. (2005). Pedagogies of engagement: Classroom-based practices. Journal of Engineering Education, 1, 87-101. 